\title{
Frontal Lobe
}

National Cancer Institute

\section{Source}

National Cancer Institute. Frontal Lobe. NCI Thesaurus. Code C12352.

The part of the brain located anterior to the parietal lobes at the front of each cerebral hemisphere. 